Paidéia, 2003, 13(25), 111-118

\title{
A ADOÇÃO NA MÍDIA: REVISÃO DA LITERATURA NACIONAL E INTERNACIONAL ${ }^{1}$
}

\author{
Adriana Pellanda Gagno ${ }^{2}$ \\ Lidia Natalia Dobrianskyj Weber \\ Universidade Federal do Paraná
}

RESUMO: O objetivo deste trabalho foi revisar a literatura nacional e internacional sobre as representações da adoção na mídia. Os estudos nacionais mais relevantes foram de Abreu, tratando da gênese do discurso midiático sobre adoção internacional, revelando diferença de abordagem entre a imprensa brasileira $e$ a francesa, a primeira considerando a adoção internacional como um "mal necessário", e a segunda mostrando-a como um gesto de caridade para com crianças oriundas de países incapazes de solucionar o problema do abandono; e de Gagno, analisando o conteúdo de revistas brasileiras de circulação nacional, Veja e Pais \& Filhos, constatando que para Pais e Filhos família ainda é a biológica, e para Veja a cobertura do tema é ampla e diversificada, talvez pelo seu distanciamento em relação às questões familiares. Dentre os estudos internacionais, há o trabalho de Waggenspack, segundo o PsycINFO, que apontou falta de orientação pública sobre adoção e a necessidade de mais pesquisas.

Palavras-chave: adoção; mídia; revisão de literatura.

\section{ADOPTION IN THE MEDIA: REVIEW OF NATIONAL AND INTERNATIONAL LITERATURE}

\begin{abstract}
The purpose of this study was to review national and international literature about the adoption represented in media. The more relevant Brazilian studies are of Abreu, dealing with the genesis of the international adoption, media discourse revealing different approaches on adoption undertaken by Brazilian and French press, the former considering international adoption as a "necessary evil", the latter as a charitable gesture towards children whose countries are unable to solve abandon problem; and of Gagno, doing content analysis of nationwide Brazilian magazines, Veja and Pais \& Filhos, showing that for Pais e Filhos family still means biological family, while for Veja the topic was covered in a more diversified and broader way, maybe due to its dettachment to family subject. Regarding the international literature, PsycINFO database, scanning shows only one article, written by Waggenspack, which indicates the lack of public awareness on the issue and the need for more research.
\end{abstract}

Key words: adoption; media; review of literature.

Apesar da adoção existir desde remotos tempos, ela permanece "esquecida" nos meios científicos ou sendo tratada de forma preconceituosa (Vargas, 1998). Segundo Weber (1996a), até recentemente poucos estudos sistemáticos sobre este assunto tinham sido realizados (especialmente no Brasil), e isto trou-

\footnotetext{
' Artigo recebido para publicação em 29/10/02; aceito em 24/01/03 2 Endereço para correspondência: Adriana Pellanda Gagno, Rua XV de Novembro, 270, Sala 503, Curitiba, PR, Cep 80020-310, E-mail: apgagno@bol.com.br
}

xe como conseqüência a generalização de casos dramáticos e a formação de preconceitos e estereótipos. Vargas e Weber (1996) afirmam que os poucos pesquisadores brasileiros que estudam as famílias adotivas referem-se à escassa bibliografia existente no Brasil e enfatizam que a maioria dos trabalhos são relatos de casos clínicos de adotivos que chegam ao consultório psicológico ou psiquiátrico, ocasionando um viés e uma generalização de que a adoção está associada ao fracasso ou a problemas. 


\section{Adriana Pellanda Gagno}

Considerando-se a necessidade de ampliar o conhecimento sobre os diferentes aspectos da adoção e visando preencher uma lacuna existente na literatura da área, posto que não há nenhum estudo de revisão sobre quais são as representações da adoção veiculadas pela mídia, julgou-se oportuno realizar o presente estudo.

O objetivo deste trabalho foi revisar a literatura nacional e internacional sobre as representações da adoção na mídia, até o ano de 2002, buscando conhecer que aspectos da adoção foram mais frequientemente abordados e de que forma.

Salienta-se a importância de se conhecer o discurso dos meios de comunicação de massa a respeito da adoção na medida em que estes têm ocupado um lugar central na cultura contemporânea. Citando Rodrigues (2000, p.145), "a análise das mensagens veiculadas pelos meios de comunicação pode produzir conhecimento considerável sobre as concepções dos agentes (jornalistas e outros profissionais da mídia) e, também, do público-alvo da comunicação (pais, professores e outros profissionais)".

Os estudos científicos nacionais sobre as representações da adoção na mídia

Revendo a literatura nacional sobre adoção, foram encontrados três estudos, sendo dois de Abreu (1994; 1998) e um de Gagno (2002), sobre como esta é vista pelos meios de comunicação de massa.

Os estudos realizados por Abreu $(1994,1998)$ trataram da gênese do discurso midiático sobre a questão adotiva internacional.

No primeiro estudo, Abreu (1994) focalizou as famílias francesas que adotaram uma criança brasileira e mostrou a forte correlação existente entre o discurso da salvação infantil e uma história pessoal marcada por um desejo insaciado de criança. Esses casais reposicionam-se diante de si mesmos e da sociedade, deixando de se representarem como incapazes de se reproduzir para assumirem uma postura de promotores de vida, sendo este o discurso difundido como legítimo pela imprensa francesa.

No segundo estudo (1998), Abreu apontou para uma diferença de abordagem da adoção entre a imprensa brasileira e a francesa. $O$ autor realizou uma pesquisa longitudinal na imprensa cearense, com base nos dados do Jornal $O$ Povo, entre os anos de $1985 \mathrm{e}$ 1987 , e constatou que, enquanto a imprensa francesa estaria mostrando a adoção, e particularmente a adoção internacional, como um gesto de caridade para com crianças deserdadas, oriundas de países incapazes de solucionar o problema da criança abandonada, a imprensa brasileira estaria difundindo este fenômeno como uma prática ruim para o Brasil e perigosa para a criança. A adoção internacional foi abordada pelo Jornal $O$ Povo como sendo um "mal necessário" ante a "vergonha nacional" da incapacidade do país de criar suas crianças, sendo apenas percebida como algo positivo "no caso individual da criança que é salva de um destino social cruel (prostituição, marginalidade) afixado na representação social que temos de sua origem de classe e de sua pertença étnica" (Abreu, 1998, p. 145-146). E, embora a idéia de estrangeiro que se tenha no país seja extremamente positiva, estando associada ao "primeiro-mundo", a algo "tipo exportação", quando se juntam os dois - a adoção com o estrangeiro - obtém-se uma "mistura explosiva", como explica Abreu (1998):

$O$ estrangeiro é agora associado no nosso imaginário àquele que de fora nos coordena e controla, incita golpes militares, implanta políticas educacionais nefastas, controla nosso mercado interno. Enfim, àquele que vem para destruir e pilhar. Nesse caso, a forma "estrangeiro" é em parte desnudada de seus significados positivos e começa a se impregnar de toda uma série de significados mais próximos daqueles normalmente atribuídos àquele que pilha nossas riquezas (nosso ouro para Portugal; nossa matéria-prima a ser transformada no primeiro mundo; nossa floresta equatorial sob constante ameaça de internacionalização, nosso café e nosso cacau, comprados a "preço de banana" por um mercado mundial injusto...). $O$ que ele quer com esse tráfico de crianças? $O$ que significa exportar bebês? ( $p$. 144-145).

O estudo de Gagno (2002) buscou conhecer as representações sobre adoção veiculadas por duas 
revistas brasileiras de circulação nacional, Veja e Pais \& Filhos, nos períodos de 1975 a 1979 e de 1996 a 2000. Foram pesquisadas, ao todo, 631 revistas. A nesquisa constatou um aumento significativo no número de publicações (reportagens e notas) que tiveram a adoção por tema ou por subtema na revista Veja, do primeiro ao segundo período estudados, na medida de 6 para 25 publicações $(316,7 \%)$, em relação ao pequeno aumento, de 8 para 10 publicações $(25,0 \%)$, observado na revista Pais \& Filhos. Considerando-se apenas as publicações que trataram diretamente sobre adoção, isto é, que a tiveram por tema, manteve-se ainda um aumento no número de publicações (reportagens e notas), em ambas as revistas, na medida de 3 para 8 publicações $(166,7 \%)$ na Veja e de 3 para $4(33,3 \%)$ na Pais \& Filhos. Verificou-se também que a revista Pais \& Filhos retratou a adoção primordialmente pelo seu viés "clássico", que visa dar filhos a quem não pode tê-los, centrando-se nos seus aspectos legais e psicológicos, mostrando que para esta revista, dirigida a pais e filhos, a adoção é vista como sendo a última solução para a esterilidade, e "família" ainda é sinônimo de familia biológica. A revista Veja, por sua vez, propiciou uma cobertura mais ampla e diversificada do tema (dados de pesquisas sobre mudanças no perfil da adoção no Brasil; adoção de órfãos de guerra; grupos de apoio à adoção; crianças retiradas judicialmente de forma dramática de famílias adotivas; caso problemático de adoção internacional; entre outros), talvez justamente em função do seu distanciamento em relação às questões familiares: pode-se falar de adoção desde que ela não faça parte da nossa vida, mas da vida das outras pessoas.

Outra menção à mídia foi feita por Weber (1996b, 1998), que a considera uma das responsáveis pela criação e/ou manutenção de preconceitos sociais sobre adoção:

\section{[...] parece que os casos em que houve} dificuldades na adoção é que são generalizados, devido às informações sobre o assunto virem da mídia e do "boca-aboca", por falta de estudos sistemáticos a respeito e até pela generalização de casos clínicos dramáticos que colocam a perda inicial dos pais biológicos como irreparável e determinante de todos os problemas. Forma-se desta maneira uma representação social limitada e errônea sobre a associação genérica entre adoção e fracasso (Weber, 1998, p. 98).

Também tem sido realizada no Brasil através da ANDI (Agência de Notícias dos Direitos da Infância) e do IAS (Instituto Ayrton Senna), desde 1996, a pesquisa Infância na Mídia, que busca analisar o comportamento editorial da mídia impressa brasileira em relação aos temas da infância e da adolescência. A coleta de dados - notícias publicadas em 50 jornais e oito revistas de circulação nacional - é realizada diariamente pela ANDI e suas agências regionais ${ }^{3}$. Além de verificar $o$ aspecto quantitativo referente ao número de matérias veiculadas, existem alguns critérios para uma análise qualitativa dos dados da pesquisa. Estes critérios são: classificar as matérias em temas e subtemas; verificar se as reportagens contribuem para a busca de soluções ou se são apenas denúncias; registrar se foi possível identificar as fontes de informação, aspecto considerado determinante da qualificação da cobertura.

A classificação das notícias em ternas que, por sua vez, contêm subtemas, permite uma percepção mais detalhada das prioridades da pauta jornalística voltada para as questões da criança e do adolescente. Os temas são: Comportamento; Cultura e Esporte; Deficiências; Desaparecidos; Direitos e Justiça; Drogas; Educação; Exploração do Trabalho; Exploração e Abuso Sexual; Meio Ambiente; Mortalidade Infantil; Saúde; Situação de Rua; Terceiro Setor e Violência. A adoção (regular ou irregular) é um dos subtemas referentes ao tema Direitos e Justiça, do qual também fazem parte: Estatuto da Criança e do Adolescente (onde se contabilizam as reportagens que expressam opiniões a favor e contra esta Lei); medidas sócio-educativas; privação de liberdade; e promoção, defesa e gestão dos direitos. Fazem parte do subtema adoção (regular): matérias relacionadas à adoção de crianças e/ou adolescentes por instrumen-

\footnotetext{
${ }^{3}$ As agências regionais da Rede ANDI são: Cipó - Comunicação Interativa (Salvador); Ciranda - Central de Notícias dos Direitos da Infância (Curitiba); Auçuba - Comunicação e Educação (Recife); Associação Educacional e Cultural "Oficina de Imagens" (Belo Horizonte); Agência Uga-Uga de Comunicação (Manaus).
} 


\section{Adriana Pellanda Gagno}

tos jurídicos legais, vítimas de abandono ou negligência e que foram deixadas em orfanatos ou abrigos de Estado. Fazem parte do subtema adoção (irregular): notícias que abordam a adoção de crianças e/ou adolescentes sem a autorização judicial, tema que "despertou interesse nos últimos anos devido às denúncias de que crianças estariam sendo vítimas de adoções ilegais nos países periféricos ou de rapto para o mercado de órgãos" (Agência Uga-Uga de Comunicação, 2000, p.18).

No ano de 2000, a pesquisa Infância na Mídia analisou 64.396 inserções de matérias, contra 10.700 do ano de 1996, revelando um crescimento do número de matérias sobre crianças e adolescentes de cerca de $500 \%$. Segundo a ANDI, "os resultados, de um modo geral, mostram que a imprensa tem refletido a mobilização social em torno dessa questão" (2001, p. 5). Não consta na pesquisa a especificação do número de reportagens sobre o subtema adoção. Apenas é referido que o tema Direitos e Justiça mantémse desde 1999 na quarta posição dentre os quinze temas, sendo os três primeiros lugares ocupados pelos temas Educação, Violência e Saúde. É mencionado também um acréscimo de $18 \%$ no número de matérias sobre Direitos e Justiça em relação ao ano de 1999, resultado das comemorações dos 10 anos do Estatuto da Criança e do Adolescente.

Verificando-se os resultados da pesquisa Infância na Mídia de 2000, obtidos pelas agências regionais a que se conseguiu acesso, pode-se concluir que o fato do tema Direitos e Justiça estar entre as primeiras posições não se deveu ao número de reportagens sobre adoção, mas principalmente à grande quantidade de notícias sobre o subtema promoção, defesa e gestão dos direitos. Na pesquisa da agência de Pernambuco, de maio a junho de 2000 , a adoção regular representou $3 \%$ do total de reportagens $(N=637)$ e a adoção irregular não foi citada; na pesquisa da agência do Amazonas, de janeiro a junho de 2000 , a adoção regular representou $2 \%$ do total $(\mathrm{N}=51)$ assim como a irregular, também com $2 \%$; e na pesquisa da agência de Curitiba, de outubro a dezembro de 2000 , a adoção regular representou $3 \%$ do total $(\mathrm{N}=237)$ e a adoção irregular representou 2,5\% do total de reportagens sobre Direitos e Justiça.

Como capítulo especial da pesquisa Infância na Mídia de 2000, foi realizada uma avaliação de como a mídia cobriu o aniversário do Estatuto da Criança e do Adolescente a partir de 66 artigos, 37 editoriais (opiniões emitidas em nome dos próprios veículos) e 689 inserções de matérias publicadas entre janeiro e julho de 2000 nos 58 veículos pesquisados. Os dados revelaram que o subtema adoção respondeu por apenas $0,64 \%$ do total de reportagens encontradas.

\section{Os estudos científicos internacionais sobre as representações da adoção na mídia}

Dentre os estudos internacionais que abordaram as representações da adoção nos meios de comunicação de massa, foi encontrado apenas um, de autoria de Waggenspack (1998), consultando o banco de dados PsycINFO, da American Psychological Association (APA), nos anos de 1887 a 2002. Este artigo, intitulado "A crise simbólica da adoção: pauta pública dos meios de comunicação populares", aponta para a falta de uma orientação pública para que se expressem símbolos positivos da adoção e que se coloque nesta uma "face" positiva, muito embora seja a adoção um modo bastante comum de se construir uma família. Segundo Waggenspack (1998), as famílias adotivas acham suas realidades diferentes das dos outros, e os resultados säo refletidos em comentários insensíveis, no questionamento de motivações, e na auto-estima prejudicada. Tais crises simbólicas sãọ o resultado da mudança de padrões e motivos de adoção; das transformações da linguagem que criam tensão; e das representações deturpadas da adoção na imprensa. É enfatizado no artigo o papel da pauta pública definida pelos media (media agenda setting) na criação da crise enfrentada pelas famílias adotivas e pelos defensores da adoção.

Nota-se que este estudo, apesar de americano, reflete uma realidade comum também ao Brasil. Os preconceitos ainda cercam a adoção, causando problemas principalmente para os que com ela estão diretamente envolvidos. Observa-se por este artigo que mesmo nos Estados Unidos, onde as agências de adoção fazem um trabalho sistemático de conscientização e esclarecimento popular sobre a adoção, esta ainda é vista como uma prática estranha, inclusive pelas famílias adotivas. Waggenspack (1998) salienta o papel decisivo da imprensa na crise 
simbólica por que passam famílias adotivas e defensores da adoção, contudo, não se pode esquecer, que comunicação é questão de cultura(s), de sujeitos e de produção, e não só de ideologias, de estruturas e de reprodução, como ensina Martín-Barbero (1999). Arbex Jr. (2001), baseado em Arendt (1976), demonstra como a rede de relações que abrange os meios de comunicação social e o público é complexa, através de um interessante exemplo:

[...] por mais que a mídia seja poderosa, não é verdade que ela sempre consiga impor livremente qualquer versão dos fatos, exatamente por depender do "contexto extralingüístico". Sempre há um conjunto de dados extralingüísticos que condicionam o uso das metáforas, expressões, jargões e clichês empregados na estruturação da narrativa. Mesmo ditaduras totalitárias, como as de Adolf Hitler e Josef Stalin, tinham de basear sua máquina de propaganda em certos consensos aceitos pela sociedade a quem se endereçavam. Hannah Arendt (1976) mostrou que Hitler, para caracterizar os judeus como fonte do mal, partiu de preconceitos já existentes na sociedade germânica. $E$, mesmo no auge do poder, Hitler teve dificuldades para impor o seu programa de "eugenia". (eliminação dos germânicos portadores de deficiência física elou mental): a fase inicial do programa (1937. 1942) permaneceu secreta, tornando-se pública apenas quando as evidências eram tantas que já não mais adiantava negar. Stalin, para liquidar os líderes da Revolução de 1917, teve de forjar os Processos de Moscou (1936-1938), procurando gerar consensos quanto ao fato de que eles eram "inimigos do socialismo" (Arbex Jr., 2001, p. 136-137).

Além deste trabalho de Waggenspack (1998), encontrou-se no PsycINFO outros 9 trabalhos indexados que, de alguma forma, relacionaram adoção e imprensa. São eles:
- Um artigo de Powers (1983), sobre algumas práticas desfavoráveis na adoção tardia, que, além de trazer reflexōes sobre os aspectos positivos e negativos da enérgica busca atual do status de "idôneo para a adoção" de crianças mais velhas, relata práticas em relação às quais estas crianças são vulneráveis, incluindo histórias na televisão e nos jornais sobre crianças à espera da adoção ("waiting children"), entre outras. Ressalta-se que são consideradas idôneas para a adoção tardia as pessoas que compreendem e estão aptas para atender às peculiaridades da adoção de uma criança que já não é mais um bebê, além de serem aprovadas nos procedimentos que visam à detecção da pedofilia, entre outras características que possam colocar estas crianças em risco.

- Um artigo de Hardy (1984), intitulado "Adoção de crianças com necessidades especiais: uma perspectiva nacional", que descreve em linhas gerais o trabalho cooperativo dos meios de comunicação de massa, organizações nacionais e locais, grupos de pais, agências de voluntários e corporações na promoção da adoção de jovens com necessidades especiais.

- Um artigo de Irving (1996), que discute os riscos do uso de publicidade para atrair novos pais para crianças que são deficientes físicas ou mentais, e apresenta um caso em que uma agência de adoção utilizou a publicidade para tal fim.

- Um artigo de Collier (1996), que comenta o artigo de Irving (1996), $€$ afirma a necessidade de realização de uma pesquisa para identificar as vantagens e desvantagens do uso de publicidade para atrair potenciais pais adotivos.

- Um artigo de Weil (1999), sobre a necessidade de uma avaliação da eficácia de três estratégias usadas para a proteção de crianças em situação de risco: o retorno aos pais biológicos, o "foster care" (transferência temporária e parcial de direitos e deveres paternos entre um adulto e outro) e a adoção. Cita os meios de comunicação de massa ao afirmar que os relatos e críticas destes - sobre as dificuldades da direção da assistência social dos Estados Unidos em proteger as crianças em risco e em destinar seus escassos recursos - é que sugeriram a necessidade de tal avaliação.

- Um resumo de dissertação, de Mcguinness (1999), 


\section{Adriana Pellanda Gagno}

sobre fatores de risco e proteção na adoção internacional de crianças da antiga União Soviética, que cita os media bastante indiretamente, ao afirmar que, apesar dos numerosos relatos na imprensa sobre os desafios da adoção de crianças da antiga URSS, nenhum estudo havia examinado, até então, seus fatores de risco e o impacto destes nas competências das referidas criariças.

- Um artigo de autoria de Adlard (1999), intitulado "Um programa educacional efetivo sobre adoção que pode ser replicado", que traz detalhes da criação, desenvolvimento e organização da "Adoption Option" - uma agência pública de educação sobre adoção fundada em 1986, em Ohio. A agência executa sua missão através de três programas, dentre os quais, um que envolve a transmissão de informações acuradas sobre adoção através dos meios de comunicação social.

- Um resumo de dissertação, de Kuhn (2001), que apresenta os resultados de uma pesquisa exploratória realizada com 50 sujeitos adultos adotados que, em resposta aos inventários "Adoption Experiences Questionnaire" (AEQ) e "Attitudes Towards Adoption Questionnaire" (ATAQ), relataram experiências positivas e negativas em relação à adoção - sendo maior o número de relatos de experiências positivas. Também são discutidos: implicações clínicas, com destaque para a intervenção junto aos pais adotivos; a importância de se aumentar a associação de imagens positivas com a adoção e, finalmente, o impacto dos retratos que a mídia oferece sobre o assunto.

- Um artigo de Hollingsworth (2002), que analisa o conteúdo de reportagens publicadas na mídia impressa, no período de 1986 a 1996, realizadas a partir de entrevistas com 93 adultos que foram adotados "transracialmente" quando eram crianças. A autora ressalta que as limitações dos dados coletados na mídia e a influência desta na construção da opinião pública e das políticas públicas são fatores que vêm enfatizar a importância de se estudar cientificamente este controverso fenômeno, que é a adoção transracial.

Observa-se que dentre estes 9 trabalhos, resumidamente descritos acima, a maioria absoluta referiu-se a estudos sobre adoções tardias, inter-raciais e de crianças com necessidades especiais, prova- velmente por estas serem as adoções possíveis nos países desenvolvidos - devido à falta de bebês saudáveis e da mesma nacionalidade dos adotantes. Estes trabalhos não tiveram por objetivo analisar como a adoção é retratada na mídia, mas não deixaram de considerar sua importante influência, positiva ou negativa, em relação à prática da adoção.

Nota-se, a partir dos dados obtidos nesta revisão de literatura, que os estudos que enfocaram as representações da adoção nos meios de comunicação de massa são recentes e bastante restritos, tanto no Brasil como no exterior.

A análise destes poucos estudos (Abreu, 1994, 1998; Gagno, 2002; Waggenspack, 1998) permite concluir que a adoção é abordada de forma diferente em diferentes veículos de mídia, dependendo do interesse que cada um tenha sobre o assunto. Neste sentido, há diferenças entre o discurso mediático brasileiro e o francês sobre a questão da adoção internacional, como verificou Abreu, assim como há diferenças de abordagem do tema entre duas revistas brasileiras de circulação nacional, sendo uma dirigida para o público em geral e outra especializada na área de família, como observou Gagno. Estas diferenças, contudo, não invalidam a constatação de Waggenspack, de que falta uma orientação pública para que se expressem símbolos positivos da adoção, mais coerentes com os fatos. Ao contrário, esta constatação revela a importância de que a pauta definida pela mídia tenha por base conceitos acurados sobre adoção - como visa a organização Adoption Option (citada anteriormente) - e não opiniões escolhidas com a única finalidade de "espetacularizar" a notícia e render publicidade.

Considerando-se a significativa participação dos meios de comunicaçăo de massa na construção social da realidade contemporânea, ressalta-se sua grande responsabilidade em possibilitar uma reorientação nos conceitos e práticas sociais, inclusive sobre a adoção, com base na divulgação de notícias completas e críticas sobre os fatos, ao invés de enrijecer ainda mais os preconceitos populares - causando prejuízos, principalmente, às famílias adotivas e às crianças à espera de adoção.

Por fim, aponta-se para a necessidade de ampliação no número de pesquisas sobre a relação entre adoção e mídia, e também para a necessidade 
uma maior divulgação de informações científicas sobre adoção na mídia brasileira e internacional.

\section{Referências Bibliográficas}

Abreu, D. (1994). Adoption et aide humanitaire: stérilité biologique, fécondité sociale et parenté symbolique. D.E.A. Université Lumière - Lyon II.

Abreu, D. (1998). Assim falou “O Povo": adoção internacional no dizer jornalístico. Em I. Barreira \& S. Vieira (Orgs.), Cultura e política: tecidos do cotidiano brasileiro (p. 133-149). Fortaleza: EUFC.

Adlard, C.R. (1999). An effective adoption education program that can be replicated. AdoptionQuarterly, 2 (3): 9-28.

Agência de Notícias dos Direitos da Infância (ANDI) \& Instituto Ayrton Senna (IAS). (2001). Infância na mídia - pesquisa ANDI/IAS, 6 (1). Brasília: ANDI.

Agência Uga-Uga de Comunicação. (2000). Infância e adolescência na mídia - pesquisa Amazonas - janeiro a junho de 2000. Manaus: UgaUga.

Arbex Jr., J. (2001). Showrnalismo: a notícia como espetáculo. São Paulo: Casa Amarela.

Collier, F. (1996). Invited comment. Child Abuse Review, 5 (5): 362.

Gagno, A.P. (2002). O percurso da adoção na imprensa brasileira. Dissertação de Mestrado, Curso de Pós-Graduação em Psicologia da Infância e da Adolescência, Universidade Federal do Paraná. Curitiba.

Hardy, D.R. (1984). Adoption of children with special needs: a national perspective. American Psychologist, 39 (8): 901-904.

Arendt, H. (1976). The_origins of the totalitarianism. New York: Harvest.

Hollingsworth, L.D. (2002). Transracial adoptees in the media: 1986-1996. American Journal of Orthopsychiatry, 72 (2): 289-293.

Irving, K. (1996). Unwanted attention: the risks of using publicity in adoption and fostering. Child Abuse Review, 5 (5): 356-361.

Kuhn, J.A. (2001). Growing up adopted: An examination of adoptees' socialization experiences. Dissertation Abstracts International: Section B: The Sciences and Engineering, 62 (5-B): 2490.

Martín-Barbero, J. (1999). Pré-Textos. Colômbia: Centro Editorial Universidad del Valle.

Mcguinness, T.M. (1999). Risk and protective factors in internationally adopted children from the former Soviet Union. Dissertation Abstracts International: Section B: The Sciences and Engineering, 59 (9-B): 4730 .

Powers, D. (1983). Some adverse practices in the adoption of older children. Residential Group Care and Treatment, 2 (1-2): 137-146.

Rodrigues, M.M.P. (2000). "Quem tem mãe tem tudo": os pais e o desenvolvimento de crianças e jovens. Em H.A. Novo \& M.C.S. Menandro (Orgs.), Olhares diversos: estudando o desenvolvimento humano (p. 143-156). Vitória: CAPES/PROIN.

Waggenspack, B.M. (1998). Adoption Quarterly I (4): 57-82.

Vargas, M.M. (1998). Adoção tardia: da família sonhada à família possível. São Paulo: Casa do Psicólogo.

Vargas, M.M. \& Weber, L.N.D. (1996). Um estudo das publicações científicas internacionais sobre adoção. Em Sociedade Brasileira de Psicologia (Org.), Caderno de Resumos da XXVI Reunião Anual da Sociedade Brasileira de Psicologia (p. 118). Ribeirão Preto: SBP.

Weber, L.N.D. (1996a). Uma olhadela na caixa de pandora: percepções e sentimentos de filhos e pais adotivos. Em Sociedade Brasileira de Psicologia (Org.), Caderno de Resumos da XXVI Reunião Anual da Sociedade Brasileira de Psicologia (p. 21). Ribeirão Preto: SBP. 


\section{Adriana Pellanda Gagno}

Weber, L.N.D. (1996b). A pesquisa sobre adoção como um fator preventivo. Em Sociedade Brasileira de Psicologia (Org.), Caderno de Resumos da XXVI Reunião Anual da Sociedade Brasileira de Psicologia (p. 18). Ribeirão Preto: SBP.

Weber, L.N.D. (1998). Laços de ternura: pesquisas e histórias de adoção. Curitiba: Editora Santa Mônica.

Weil, T.P. (1999). Children at risk: outcome and cost measures needed. Child Psychiatry and Human Development, $30 \cdot(1): 3-18$.

Este trabalho deriva de parte da dissertação de mestrado da primeira autora, orientada pela segunda, e defendida junto ao Programa de Mestrado em Psicologia da Infância e da Adolescência da.Universidade Federal do Paraná. 